\title{
Quizlet as a Tool for Enhancing Autonomous Learning of English Vocabulary
}

Nguyen Thanh Thuy ${ }^{1 *}$, Nguyen Dinh Tri ${ }^{1}$, Nguyen Dang Le Quoc Khanh ${ }^{1}$, Mai Huy Hoang ${ }^{1}$, Le Thi Thanh Xuan ${ }^{1}$, Dao Nguyen Anh Duc ${ }^{1}$

\author{
${ }^{1}$ Banking University Ho Chi Minh City, Faculty of Foreign Languages, Ho Chi Minh City, Vietnam \\ *Correspondence: Nguyen Thanh Thuy, Banking University Ho Chi Minh City, Vietnam. E-mail: \\ nguyenthanhthuy120501@gmail.com
}

DOI: https://doi.org/10.54855/acoj221319

\section{ABSTRACT}

L2 vocabulary learning seems to be one of the biggest challenges for many language major students as lexical knowledge involves productive understanding of its many components, including the form, meaning, and application of the terms (Nation, 2001). It is, therefore, necessary to find appropriate language education tactics and instruments for the successful and efficient acquisition of this aspect of the L2. Among advancements in the field of educational technology, Quizlet was invented with the hope that learners could effectively acquire L2 vocabulary in the absence of the teacher. In this study, the researchers want to figure out if Quizlet is helpful in assisting students in learning English vocabulary. They would also like to identify the difficulties that learners may encounter when using the application for their self-study. A quantitative survey was conducted on 100 English major freshmen and sophomores at a university in Ho Chi Minh City, Vietnam. Results reveal that Quizlet plays an active role in facilitating self-study of English vocabulary. A remarkable finding is that an application seems to provide an entertaining learning environment, which in turn enhances learning motivation. Besides, a couple of limitations of the app, namely distracting ads and limited mobile learning functionality, have also been identified.

Keywords: Quizlet, autonomous learning, English vocabulary

\section{INTRODUCTION}

\subsection{Background of the study}

Nowadays, students are referred to as "Digital Natives" since they are comfortable with technology, computers, and the Internet, as well as video games (Prensky, 2001). That has resulted in the necessity of applying information technology (IT) to teach and learn. In addition, technology has played an essential role in English teaching and learning for many countries in the world (Eady \& Lockyer, 2013). It has been used to help teachers adjust to activities in class. Also, learners enhance the language learning process and improve their skills in a short time by utilizing technology and its services.

The learning of vocabulary is a critical element in enhancing knowledge and reading 
comprehension of a second language (L2). Yet, this is perhaps the biggest challenge for many linguistic students because vocabulary knowledge involves a productive understanding of its many components, including the form, meaning, and application of the term (Nation, 2001). Thanks to the help of Quizlet, students may efficiently self-study vocabulary, resulting in significant vocabulary improvements (Thi \& Satomi, 2021). Recently, to keep up with the trends and encourage students to approach IT, Vietnamese teachers have also recommended that students use Quizlet to acquire English vocabulary as a better way to learn English.

According to Rohmatillah research (2014), students faced a lot of difficulties when they learned vocabulary. It is hard to approach quickly in a short time because they have never discovered the drive and excitement to face the challenge of acquiring new English knowledge. Finding the most appropriate language education tactics and instruments for effective learning vocabulary is necessary. Van et al. (2021) identified that technology could help students learn English productively. Besides, knowledge also could learn from technology more easily if they took advantage of its usability.

For these reasons, this paper would give students the advantages of utilizing Quizlet in developing vocabulary acquisition, especially BUH Language freshmen and sophomores. It is necessary to give them insights into adopting the Quizlet trending learning method.

\subsection{Research objectives}

In this study, specific aspects of using Quizlet in vocabulary acquisition will be explored. Next, the study would figure out if the Quizlet application is helpful in assisting students in learning L2. Furthermore, we want to identify the difficulties which students can have when they use Quizlet.

\subsection{Significance of the study}

From the helpfulness and difficulties of using Quizlet in acquiring vocabulary and some data collected, we will assess the level of effectiveness when students apply Quizlet to learning. To sum up, all of the results in this research might help students, who major in the English language at Banking University, make the best of the benefits from Quizlet in boosting students' L2 learning motivation and autonomy.

\subsection{Research question}

To fulfill the purpose of the study, the survey sought to answer the following research questions:

How do the learners use Quizlet for vocabulary?

How effectively does Quizlet help learners with vocabulary?

What are the difficulties when learners use Quizlet? 


\section{LITERATURE REVIEW}

\subsection{General overview of Quizlet}

According to Wright (2016), Quizlet is a digital flashcards platform that allows users to construct their flashcards and study them through various learning modes. It is one of the most popular flashcards programs, with over fifty million monthly users as well as over four hundred users--generated study sets (Matthew, 2019). Currently, with different types of learning modes, Quizlet gives the student interest in trying out various modes and provides them with 'richer ways' to study (Ravipati, 2017).

Table 1. Features of Quizlet

\begin{tabular}{|c|c|c|}
\hline Features & Description & $\begin{array}{l}\text { Mobile } \\
\text { App }\end{array}$ \\
\hline Learn & $\begin{array}{l}\text { There are three types of tasks: Flashcard, multiple-choice item, and } \\
\text { typing the required answer. Users can personalize this activity by } \\
\text { selecting one of the three options. }\end{array}$ & Available \\
\hline Flashcards & $\begin{array}{l}\text { Users can create their flashcards. It could optionally be added self- } \\
\text { explanation, audio,... Digital flashcards can be flipped by mouse } \\
\text { clicks or tabs on screens to show definitions or visuals that illustrate } \\
\text { the term. }\end{array}$ & Available \\
\hline Spell & $\begin{array}{l}\text { After listening to the audio prompts, learners are required to type } \\
\text { the words correctly. If the word is spelled incorrectly, the correct } \\
\text { answer will be read letter by letter while appearing on the scene. }\end{array}$ & $\begin{array}{c}\text { Not } \\
\text { available }\end{array}$ \\
\hline Write & $\begin{array}{l}\text { Users are given some space to write the definition or meaning of a } \\
\text { word learned in 'flashcards' functions. }\end{array}$ & Available \\
\hline Test & $\begin{array}{l}\text { Four types of tests are included: true/false, multiple-choice, } \\
\text { matching, and typing the answer. Learners can customize this } \\
\text { activity. }\end{array}$ & Available \\
\hline Match & $\begin{array}{l}\text { Learners will join in a game that needs to match keywords to their } \\
\text { definitions (or accompanying visuals) as rapidly as possible. When } \\
\text { learners complete each question, the app will show the score and } \\
\text { rank among other learners. }\end{array}$ & Available \\
\hline Gravity & $\begin{array}{l}\text { Another game in which the terms emerge on approaching asteroids. } \\
\text { Before the falling asteroid hits the planet, students must type the } \\
\text { corresponding definition of the term. }\end{array}$ & $\begin{array}{c}\text { Not } \\
\text { Available }\end{array}$ \\
\hline Live & $\begin{array}{l}\text { This is a feature that needs four or more people. Students will need } \\
\text { to connect to http://quizlet.com/live and input the code provided by } \\
\text { the teachers. Participating in the teacher's activity, students will } \\
\text { have to team up to compete with the other group. }\end{array}$ & $\begin{array}{c}\text { Not } \\
\text { Available }\end{array}$ \\
\hline
\end{tabular}




\subsection{The effectiveness of Quizlet in the acquisition of vocabulary}

To begin with, motivation may be defined as combining both the desire for language acquisition and the desire to learn the language (Gardner, 1985, cited by Alizadeh, 2016). Many previous studies proved that Quizlet could create a motivation to arouse interest in learning from within students' consciousness. According to Rezaei et al. (2014), the mode of Quizlet activity method was an ideal medium for making students enjoy learning the words. It was indicated that students were motivated to acquire vocabulary when they applied it. Some of the interview's findings (Anjaniputra \& Salsabila, 2018) have proved that Quizlet provided a new, enjoyable way of vocabulary learning for students due to various features of the application. Those aspects provided a fun experience for students to sense a new method of learning. In Skattenborg's research (2020), teachers thought Quizlet was effective when they utilized it appropriately. It was good for repetition, motivating pupils, and varying the lessons. Students also believed Quizlet was motivating and added variety to their learning process.

Besides motivation, another benefit of Quizlet is to promote active learning. Active learning consists of short course-related individual or small-group activities that all students in a class were called upon to do, alternating with instructor-led intervals (Felder \& Brent, 2009). Thus, to learn vocabulary, only using a motivation to boost up oneself perhaps is not enough. According to many studies, more learners are interested in autonomous learning. These researches indicated that the Quizlet application gave learners the freedom to learn on their computers and cellphones (Vargas, 2011; Barr, 2016; Kálecký, 2016); students took advantage of benefit from the "spell section" to enhance their word spelling (Vargas, 2011; Kálecký, 2016) and students may focus their progress and discover where parts of their vocabulary were lacking (Kálecký, 2016). Furthermore, Korlu \& Mede (2018) stated that Quizlet effectively helped the students' performance and made them more self-governing in learning vocabulary since the design of Quizlet was appropriate for autonomous learners. Setiawan \& Wiedarti (2020) also demonstrated that students felt more enthusiastic, did not get bored, and showed a high level of interest when they could self-study vocabulary using the Quizlet application.

Next, Quizlet is effective in allowing the students to improve their achievement. Among various study modes available in Quizlet, Franciosi (2017) stated that game-based learning on Quizlet could significantly promote English vocabulary acquisition. The research outcome showed that many students held more optimistic views about using Quizlet game-based learning platform to build up their TOEIC vocabulary and exhibited considerably greater confidence in their TOEIC satisfactory test marks. On the other hand, Lees and Mcnee (2015) also indicated that students who utilized the Quizlet application were more motivated than those who did not. The overall score earned by the user of the application was much greater than that of the non-user. According to Chien (2015), students found online vocabulary websites, particularly Quizlet, stimulating and useful for vocabulary acquisition. Participants in his study also thought that utilizing Quizlet boosted their language knowledge. According to Korkealehto and Siklander (2018), who based their findings on students' diary entries and questionnaire replies, students thought Quizlet improved their writing and oral language skills. Similarly, Nguyen and Vo's 
(2021) research participants also improved their language abilities by utilizing English learning applications like Quizlet.

Quizlet may greatly improve academic vocabulary acquisition. Students could find the learning experience to be more pleasant and beneficial, which motivated them to spend time studying on their own with Quizlet (Gilbert, 2016). In addition, Sanosi (2018) discovered that by using the Quizlet application via a smartphone, students might learn new words themself. In doing the assignments provided in Quizlet, both of the study's examinations showed that most students prefer to work independently and confidently with assignments given in the application on their own.

\subsection{The challenges in using Quizlet}

Although Quizlet was a highly rated vocabulary learning platform, at the same time, there were limitations in the user experience. Some of its features were only available on the website rather than in mobile apps (Dizon, 2016). Like Wikipedia, Quizlet permitted everyone to make and share a study set, so there was no assurance the data was exact. One grammatical mistake in another person's cards could lead them to consider some wrong data, miss inquiries on a test, and get a poor quality they did not anticipate getting (Bri, 2019).

Furthermore, some students appeared distracted while learning vocabulary and were occupied with different applications like Instagram and Facebook (Setiawan \& Wiedarti, 2020). Besides, if students used Quizlet's free version, ads would be displayed on each website page (Bri, 2019). A few advertisements were barely noticeable; however, they could be oppressive. Thus, if students need the best taking-in experience from Quizlet, they should pay for extra administrations.

In short, this section helped to find out the interplay between Quizlet and autonomous student learning and some aspects that have not been clarified in previous research. The researchers explored that Quizlet created an attractive environment for students in the acquisition of vocabulary. It provided many functions for students to get hold of vocabulary and boost them to improve their motivation. Moreover, students were more interested in using game-based learning than the non-game approach. Furthermore, although they were distracted by other platforms, there was no denying the fact that Quizlet played a vital role in enhancing learners' autonomy. However, almost all of the studies only focused on one specific group of students, and non-comparison have been made among the different groups. Thus, the purpose of this study is to conduct the filling gaps by comparing the result between freshmen and sophomores. In addition, this research is to establish if Quizlet can increase the effectiveness of L2 vocabulary learning and assess the experiences of two groups. 


\section{METHODS}

\subsection{Pedagogical Setting \& Participants}

The research subjects included 100 Business English-major students in Banking University Ho Chi Minh City. The sample of this study was collected from 50 freshmen and 50 sophomores. All of the participants have experienced the English environment of the university. Most of the freshmen and sophomores were introduced to Quizlet by teachers. However, freshmen were new to it, while sophomores used it for a while. This difference helped the study assess how they apply Quizlet in learning vocabulary. Thus, the results collected from this sample can show the difference between freshmen and sophomores.

\subsection{Design of the Study}

This study employed the quantitative research method through the mixture of non-experimental and cross-sectional study designs. Due to the nature of the research, the questionnaire was posted on Facebook groups and collected answers from participants once. The frequency of usage and attitudes in utilizing the Quizlet application were investigated and performed a retrospective based on students' experiences.

The data collection tools were a questionnaire in Google Forms combining a 5-point Likert scale. The content of the questionnaire was based on the research questions in this study and some ideas from the questionnaire of Gilbert's research (2016). We modified and supplemented it to suit the reality of this study. The scale included 11 items related to the motivation and active learning factors affecting freshmen and sophomores' vocabulary learning habits. On a 5-point Likert scale, response options were presented: ranging from strongly disagree, disagree, not sure, agree, and strongly agree.

According to the characteristics of this study, quota sampling was applied because of the limited time for primary data collection. The procedure of collecting primary data lasted two weeks. It consisted of finding the general situation of students using Quizlet, creating a questionnaire, modifying it in line with the real situation, posting the official questionnaire on the Facebook forum to all of the participants, and receiving their responses in a week. 


\section{FINDINGS AND DISCUSSIONS}

\subsection{Research question 1: How do the learners use Quizlet for vocabulary? \\ 4.1.1 time}

Table 2.

The percentage of the Quizlet time usage in Freshmen and Sophomore year (\%)

\begin{tabular}{lcc}
\hline & Freshmen & Sophomores \\
\hline \hline Under 20 minutes each week & 37.50 & 58.18 \\
From 20 to 40 minutes each week & 33.33 & 27.27 \\
From 40 to 60 minutes each week & 12.5 & 9.09 \\
Above 60 minutes each week & 16.67 & 5.46 \\
\hline
\end{tabular}

Table 2 illustrates how much time students spent studying vocabulary on Quizlet outside of class. The majority of freshmen and sophomores did not use a considerable amount of time for Quizlet. Based on Figure 1, 37.5\% of the freshmen and 58.2\% of the sophomores spent less than 20 minutes each week. The percentage of sophomores increases by $20.7 \%$ percent more than freshmen. Notably, in the "20 to 40 minutes per week" and "40 to 60 minutes per week" average segments, the percentage of first-year students is also $6 \%$ higher than second-year students by $6 \%$ and $3.4 \%$. In addition, a few of the students used more than one hour a week to study vocabulary, especially the sophomore (Freshman $=16.7 \%$ and Sophomore $=5.5 \%$ ).

These findings show that most of the students in this study used Quizlet as a support mechanism for vocabulary development in addition to traditional learning methods, which is similar to the results found by Burston (2014). To explain why first-year students spend more time than second-year students, Nakata (2006) demonstrated that freshmen want to increase their motivation to learn and achieve. Thus, they improved their learning experience and the extent to which they remember what they have learned. However, the percentage shows that students have not yet chosen Quizlet as a habit to learn every day. Besides, they may spend their time on other works outside class. The evidence is the decreasing number of freshmen and sophomores studying from 20 to 40 minutes, 40 to 60 minutes, and above 60 minutes per week. The reason for this was explained logically by Jogja English Teachers Association (2018). They also found some activities that make students have no time to learn outside class, such as doing assignments, part-time jobs, and doing house chores. 


\subsubsection{Function}

Table 3.

The percentage of the Quizlet functions usage of Freshmen and Sophomores (\%)

\begin{tabular}{lcc}
\hline & Freshmen & Sophomores \\
\hline \hline Flashcards & 33.33 & 37.08 \\
Learn & 20 & 16.85 \\
Test & 20 & 20.22 \\
Spell & 14.67 & 8.43 \\
Match & 9.33 & 14.5 \\
Live & 2.67 & 3.37 \\
\hline
\end{tabular}

First, based on the data, the Flashcard rate is over $30 \%$, but the Live rate is below $4 \%$. In particular, the rate of Flashcard usage in the freshmen year is $33.33 \%$ and in the sophomore year is $37.1 \%$, which is the highest percentage of Quizlet functions mentioned in the survey. In contrast, Live is the least chosen, with $2.7 \%$ in the freshman year and $3.4 \%$ in the sophomore year. Besides, there is a difference between the two research subjects in Match and Spell. Firstyear students like using Spell, but second-year students are interested in Match.

According to the survey, students are interested in Flashcards more than other functions. Flashcard allows students to create a new study set every time they like easily. Thus, the figures show freshman and sophomore students tend to set up flashcards to learn vocabulary because of their essential capability. In addition, the customization of Flashcards helps students learn vocabulary that is not only requested by teachers but also requested by themselves. That is true with Agung Ginanjar Anjaniputra \& Vina Aini Salsabila analysis (2018) about the benefits of Flashcard. For the Live function, the reason why the lowest percentage in both years is that students must pay money to use it. Most of the time, students only use Live in the classroom when their teacher creates Live game-based and gives the code to participants. However, the specific explanation for this has not been discovered in previous studies yet.

Finally, there is a difference between the percentage of students who use Match and Spell. Spell function is used more among freshmen students because they do not have specialized vocabulary background, even if they don't know those words before. When using Spell, Quizlet helps them practice pronunciation and memorize vocabulary quickly. Students only touch the screen and match possible words and meanings together regarding the Match function. This function is both easy to use and saves time in line with the point of view that Hougham (2019) demonstrated. Thus Match is more suitable for students with a vocabulary background as sophomore students.

Hence, from these findings, Quizlet functions can all help students acquire vocabulary effectively. Based on the results, most freshmen and sophomores tend to use Flashcards more than other functions because of the ease and convenience it brings. 


\subsection{Research question 2: How effectively does Quizlet help learners with vocabulary?}

\subsubsection{Motivation}

Figure 1.

The mean value of students motivation in using Quizlet

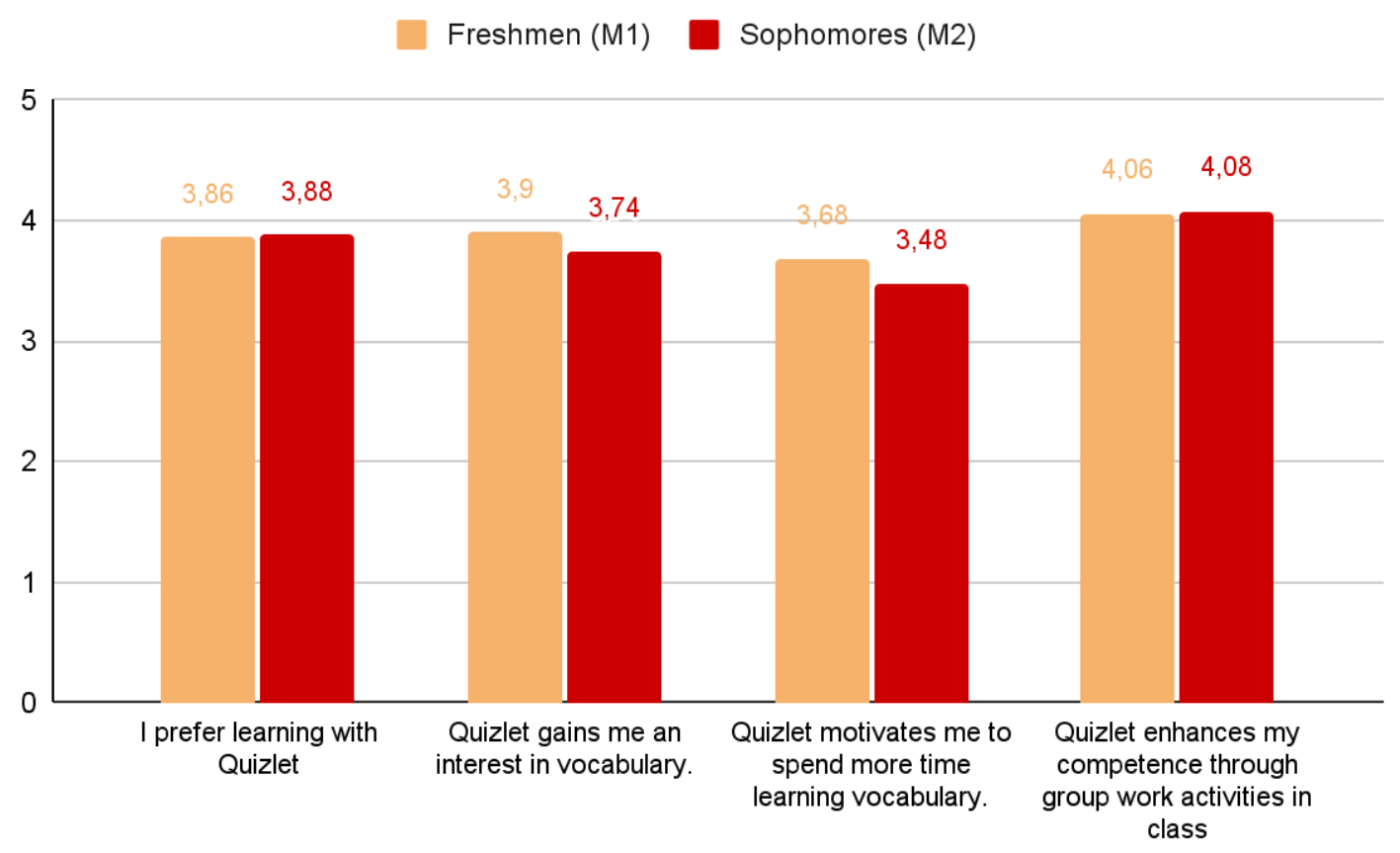

Based on the survey, it is found that the lowest mean score of both groups was the same item (Quizlet motivates me to spend more time learning vocabulary). In detail, the mean value is quite the same $(\mathrm{M} 1=3.68, \mathrm{M} 2=3.48)$, which is at a moderate level. It indicates that most of the freshmen and sophomores did not spend much time using Quizlet to learn vocabulary. However, it is found that the motivation which Quizlet has brought back can not be denied, which is shown through the other items.

The statement "Quizlet enhances my competence through group work activities in class" has the highest mean score from both groups $(\mathrm{M} 1=4.06, \mathrm{M} 2=4.08)$. This can be considered that Quizlet is helpful in learning vocabulary and helps enhance students' learning performance and competitiveness, especially the Live function on the Quizlet application. Normal lessons in class will become more exciting with Quizlet digital games. In Forsythe's study (2016), he had applied Quizlet Live to his lessons and asked for the students' feedback. As expected, his students commented that they really enjoyed the game, and above all, Quizlet Live certainly helped them with vocabulary acquisition. Moreover, Quizlet Live can motivate students to consider autonomous study as a way to prepare for the game and, through that, increase the effectiveness of their classroom participation (Sophia, 2016).

In general, the mean score of the survey is at a moderate to high level of approval. $(3<\mathrm{M}<5)$. This somehow indicates the effectiveness of Quizlet on motivating vocabulary acquisition of 
freshmen and sophomores at Banking University.

\subsubsection{Active learning}

Figure 2.

The means value of students' initiative in using Quizlet

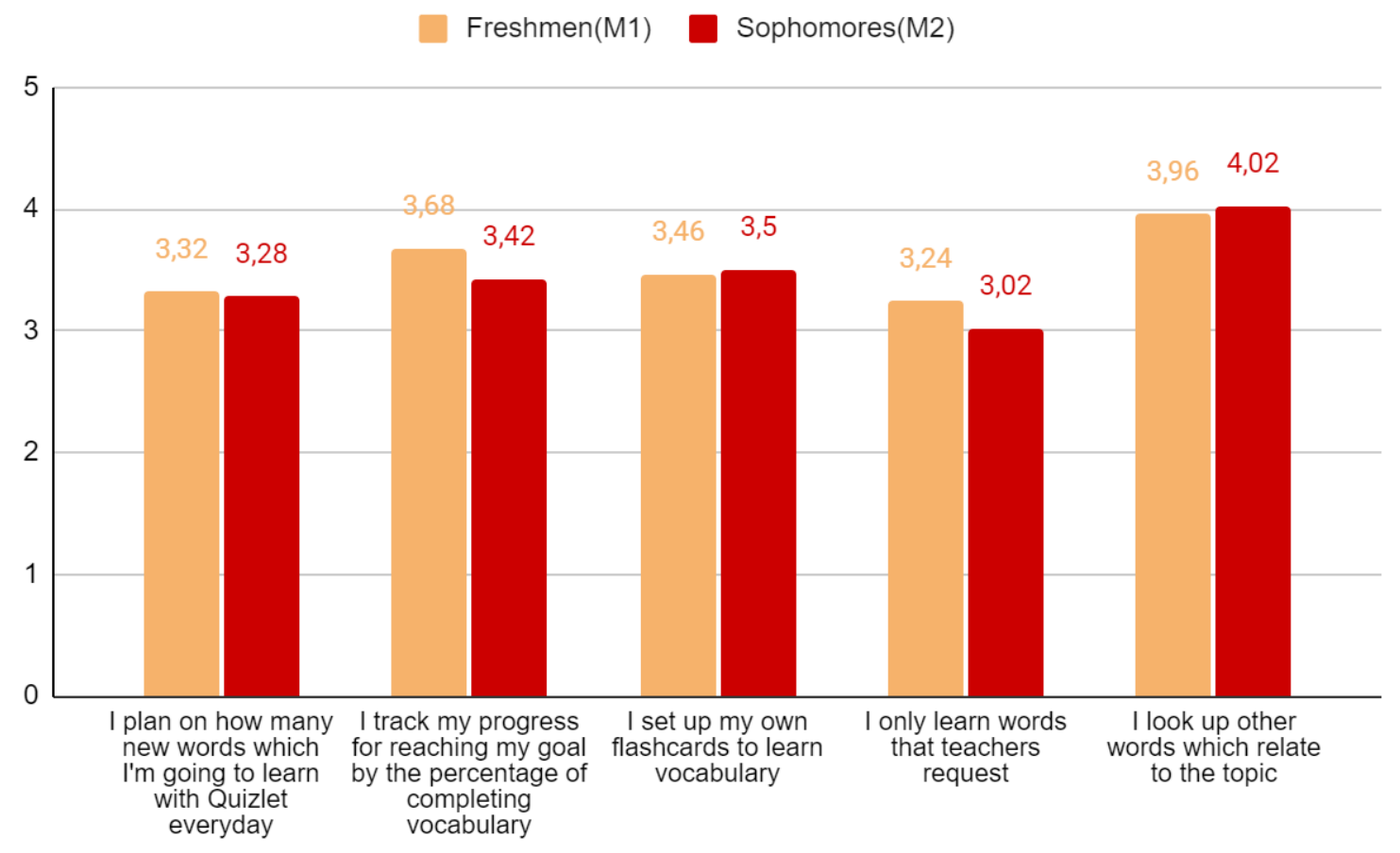

Figure 2 compares the mean values in terms of each criterion to clarify the freshmen and sophomore differences. In particular, the statement "Quizlet enhances my competence through group work activities in class" has the highest level of agreement with M1=3.96 and M2 = 4.02. Based on Appendix 2, 82\% of freshmen and $72 \%$ of sophomores tend to actively search for another vocabulary related to the lesson through the Quizlet app. The findings demonstrate the effect of Quizlet on students' learning, especially in increasing competitiveness. In addition, as the motivation section mentioned, freshmen and sophomores are motivated to get higher scores in competition in class, so both consciously enlarge their vocabulary to have plus-point in class. The findings are quite similar to Gilbert's (2016) research. Using Quizlet becomes a useful strategy to motivate studying L2 vocabulary, as shown by the important gains the students want to achieve on their scores. Although the percentage of sophomores looking up other new words is higher than that of freshmen, there is no big difference in this ratio.

Next, item two, "I track my progress for reaching my goal by the percentage of completing vocabulary," got the second-highest score with the exact means $\mathrm{M} 1=3.68$ and M2 $=3.42$. This figure shows that students can detect how much they lack knowledge about that topic and have a direction to adjust their way of learning. Students are accustomed to using technologies in learning vocabulary, so applying Quizlet becomes an easy and exciting method. That has been 
demonstrated in Kálecký's (2016) and Sanosi's (2018) study.

Moreover, thanks to the motivations and benefits that Quizlet provides, the freshmen and sophomore students viewed the use of Flashcards in acquiring vocabulary positively outside class. As Figure 2 mentioned, Flashcard is the most chosen function, so the mean results show that students were quite fond of creating flashcards with the value M1=3.46 and M2 $=3.5$. It showed Flashcard as a way to promote and develop learner-centered learning environments. These results demonstrate that most of the students in this study made an effort to take advantage of the benefits of the Flashcard function to improve their memory and review vocabulary better. It is similar to the research shown by Burston (2014) and Taylor \& Francis study (2020).

As a result, according to the results, it is clear that the students perceived Quizlet to be beneficial in terms of their L2 development. Most of the figures about the level of motivation and active learning show a concurrence trend. That proves that Quizlet creates a fun environment that motivates the freshmen and sophomore students in vocabulary acquisition. Thanks to those motivations, students are aware of the importance of expanding their knowledge and always actively spend time promoting self-study outside of class time.

\subsubsection{Outcome}

\section{Figure 3.}

The mean value of student's outcome after using Quizlet

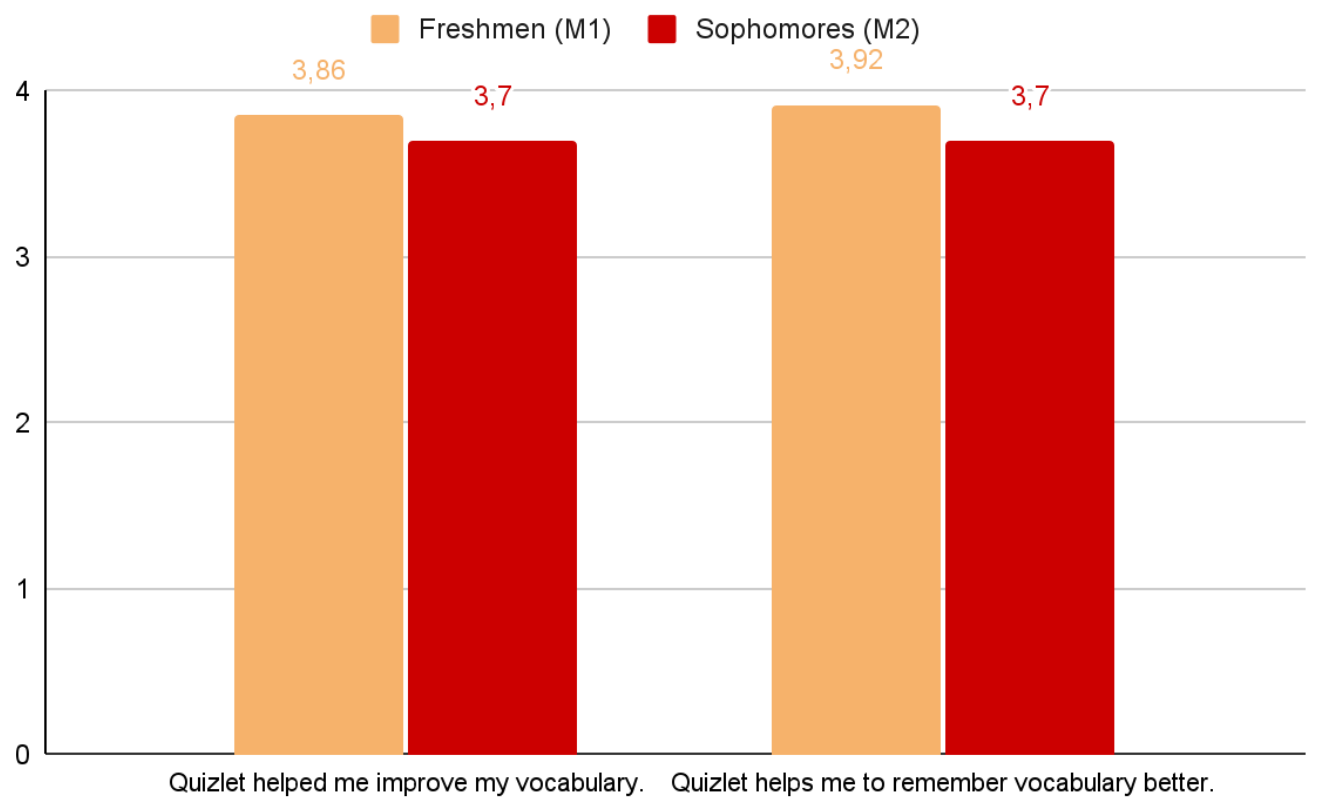

According to the survey, both freshmen and sophomores have admitted that they can better memorize vocabulary with Quizlet. This has been demonstrated by the high level of approval of the two items "Quizlet helped me improve my vocabulary." (M1=3.86, M2=3.7) and "Quizlet helps me to remember vocabulary better." (M1=3.92, M2=3.7). This result can be explained by 
various features of Quizlet, which provides an updated, enjoyable and effective way of vocabulary learning for students (Anjaniputra, 2018).

\subsection{Research question 3: What are the difficulties when learners use Quizlet?}

Although Quizlet is perceived as a good tool, there are still limitations and imperfections. When students were asked about difficulties in using Quizlet, the two most frequent answers were features limited in Quizlet mobile and being distracted by ads and social media. With more than $40 \%$ of choices from the sample, advertising and social media become a barrier to affect the freshmen and sophomore students. This finding indicates that it is difficult for them to turn off notifications from social networking applications or ignore promotional purchase ads from floating e-commerce platforms on the learning platform. This is the same with Setiawan \& Wiedarti's study (2020) because it also demonstrates students can be quickly distracted when they study Quizlet vocabulary.

Furthermore, $33 \%$ of freshmen and $30 \%$ of sophomore students were also disappointed that the app offers fewer features on mobile. Eight learning modes are available in the website application interfaces. However, only five are offered in the mobile application interface (Sanosi, 2018). With this finding, students might have difficulty applying all the functions to learn vocabulary at the same time though the mobile phone is a useful device that can be brought everywhere.

The least selected difficulty is the information and knowledge containing errors (freshmen= $10 \%$ and sophomore $=9 \%$ ). The percentage shows that vocabulary sets on Quizlet have good reliability. This is not the same view as Setiawan \& Wiedarti's study (2020) that students may learn some of the incorrect or ambiguous word meanings. Although students can not be immune to the wrong learning materials, this only happens with self-study students. Thus, students could access materials that their teachers have prepared on Quizlet.

In the second-year survey, there are two other difficulties mentioned. "Quizlet does not have strict rules to use its features well" and "Create vocabulary cards with sounds for extra money." However, the main reason that hinders the learning process of the freshmen and sophomore students is being distracted by pop-up ads, social networks, and limited mobile learning functionality. To sum up, students need to practice self-control or set study times to control distractions. Besides, students can spend time learning on the computer to use the Quizlet functions fully, and signing up for Quizlet Go is a way to handle annoying ads on this application. 


\section{Table 4.}

The percentage of difficulties in using Quizlet

Items

Distracted by ads or social media (Facebook, Instagram...)

Quizlet mobile does not have some features as on the website

Limitation in providing learning information materials

Definitions of some words are inaccurate

Others
Freshmen Sophomores

$\begin{array}{cc}42 \% & 41 \% \\ 33 \% & 30 \% \\ 15 \% & 17 \% \\ 10 \% & 9 \% \\ 0 \% & 3 \% *\end{array}$

* Others: "Quizlet does not have strict rules to use its features well."

"Create vocabulary cards with sounds for extra money."

\section{CONCLUSION}

Based on the finding, Quizlet could help students improve their vocabulary so that they can have enough motivation and have an interest in vocabulary learning. Besides, it becomes an effective application for them by assisting students in approaching new words or assessing their learning progress. However, some limitations need to be solved, such as the less usage time of students each week, distracting ads and social media, or some paid functions.

From these problems, the authors of this research can put forward some potential solutions for schools, lecturers, and students. School directors expressed that they indicated quite high intentions to assist lectures and non-commercial activities of their students and teachers (Geuens, De Pelsmacker \& Mast, 2002). Thus, by sponsoring Quizlet packages or purchasing sharable accounts, schools can help many students approach Quizlet functions. Full access to Quizlet Plus might pique students' curiosity and interest. It might encourage them to use and experience. Students would enjoy and desire the study method of Quizlet. Next, lecturers should have more recommendations about Quizlet or give students homework on Quizlet. This way, students can effectively exploit the benefits of Quizlet and increase time for study (Gilbert 2016). Due to the interest and support from school and lecturers for students to effectively exploit the benefits of Quizlet and increase time for study, this habit would increase the time students actively learn vocabulary and improve their English skills. Students who have good study habits will know how to build their learning plan and self-study as they devised (Julius \& Evans, 2015).

Although this study revealed positive results, it is not without its shortcomings. First, because of the impact of the pandemic, the survey had to collect samples online and was limited to 100 English first year and second-year students. This limitation made the results less general. Also, this study focused on students who major in the English language at Banking University Ho Chi Minh City, so these results cannot be applied to students of any majors or schools. Lastly, it would be interesting if a future study looked at the differences between general vocabulary and specific vocabulary; consequently, the results only indicated the Quizlet effectiveness to 
general vocabulary. It would be worthwhile if future studies compare this difference and expand the research object to get more data for further analysis on vocabulary acquisition.

\section{ACKNOWLEDGEMENT}

We deeply appreciate the insightful comments of Ms. Dao Nguyen Anh Duc - our mentor and lecturer of the Faculty of Foreign Languages of Banking University, Ho Chi Minh City, on our earliest drafts and whole study. And we wish to thank her support during the process of our work and participation in the conference.

\section{REFERENCES}

Anjaniputra, A. G., \& Salsabila, V. A. (2018). The merits of Quizlet for vocabulary learning at tertiary level. Indonesian EFL Journal, 4(2), 1-11. doi: 10.25134/ieflj. v4i2.1370.

Barr, B. (2016). Checking the Effectiveness of Quizlet as a Tool for Vocabulary Learning. The Center for ELF Journal 31, 36-48. doi:10.15045/ELF_0020104.

Bri, S. (2019). Pros and cons of using a Quizlet in your classroom. Retrieved July 23, 2019, from https://www.aeseducation.com/blog/quizlet-pros-cons

Dizon, G. (2016). Quizlet in the EFL classroom: Enhancing academic vocabulary acquisition of Japanese university students. Teaching English with Technology, 16(2), 40-56. Retrieved from http://www.tewtjournal.org

Eady, M. J., \& Lockyer, L. (2013). Tools for learning: technology and teaching strategies: Learning to teach in the primary school. Queensland University of Technology, Australia, 71-89. Retrieved from https://scholars.uow.edu.au/display/publication76376

Franciosi, S. J. (2017). The Effect of Computer Game-Based Learning on FL Vocabulary Transferability. Educational Technology \& Society, 20 (1), 123-133.

Geuens, M., De Pelsmacker, P., \& Mast, G. (2002). Attitudes of school directors towards inschool marketing: an exploratory study. Young Consumers, 3(3), 57-67. https://doi.org/10.1108/17473610210813547

Hakan, K. \& Enisa, M. (2018). Autonomy in Vocabulary Learning of Turkish EFL Learners. The Eurocall Review, 26(2), 58 - 70.

Julius, M., \& Evans, A. S. (2015). Study of the relationship between study habits and academic achievement of students: A case of Spicer Higher Secondary School, India. International Journal of Educational Administration and Policy Studies, 7(7), 134-141. https://doi.org/10.5897/ijeaps2015.0404

Kalecky, R. (2016). Quizlet vs. Vocabulary Notebook: The Impact of Different Methods of Storing and Revising Vocabulary on Students' Progress. Retention and Autonomy. Unpublished Master's thesis, Masaryk University. Retrieved from https://is.muni.cz/th/qzvxl/Roman_Kalecky___Quizlet_vs.pdf 
Lees, D., \& Mcnee, G. (2015). Effects and impressions of digital vocabulary-learning vs. paperbased. Humanities Review, 20, 143-164.

Matthew, G. (2019). Celebrating 2019 and Quizlet's impact. Retrieved December 13, 2019 from https://quizlet.com/blog/2019-impact-report

Nadezhda V. B., Larisa L. Z., Irina G. A., Lidia, E. M. \& Alexander, V. C. (2019). Media Promotion Role of Economic Vocabulary: Specific Features and Functions in Presentation and Advertisement. Online Journal of Communication and Media Technologies, 9(2), e201907.

Nguyen, T. N. Q., \& Vo, N. T. T. (2021). The Need of Applying English Learning Apps to HelpVan Lang University Students Improve Their Spoken English Performance. AsiaCALL Online Journal, 12(2), 72-86. Retrieved from https://asiacall.info/acoj/index.php/journal/article/view/33/22

Prensky, M. (2001). Digital Natives, Digital Immigrants Part 1. On the Horizon 9, 1-6.

Rezaei, A., Mai, N., \& A., P. (2014). The effect of mobile applications on English vocabulary acquisition. Jurnal Teknologi (Sciences \& Engineering), 68(2), 73-83.

Richard, M. F., \& Rebecca, B. (2009). Active learning: An introduction. Retrieved from https://www.engr.ncsu.edu/stem-resources/legacy-site/education-related-papers/activelearning-introduction/

Ryan, R. M., \& Deci, E. L. (2000b). Self-Determination Theory and the Facilitation of Intrinsic Motivation, Social Development, and Well-Being. American Psychologists, 55(1), 68-78.

Sanosi, A. B. (2018). The effect of Quizlet on vocabulary acquisition. Asian Journal of Education and e-Learning, 6(4), 71-77.

Setiawan, M. R., \& Wiedarti, P. (2020). The effectiveness of Quizlet application towards students' motivation in learning vocabulary. Studies in English Language and Education, 7(1), 83-95. doi:10.24815/siele.v7i1.15359

Skattenborg, V. (2020). Using Quizlet for Vocabulary Learning-is Quizlet more effective and motivating than non-digital methods? (Master's thesis). Retrieved from https://hiof.brage.unit.no/hiofxmlui/bitstream/handle/11250/2723664/Skattenborg_Vibeke.pdf?sequence $=1$

Sri, R. (2017). New Quizlet Feature Lets Students Customize Study Materials with Pictures. Retrieved from https://thejournal.com/articles/2017/08/24/new-quizlet-feature-letsstudents-customize-study-materials-with-pictures

Van, L. K., Dang, T. A., Pham, D. B. T., Vo, T. T. N., \& Pham, V. P. H. (2021). The Effectiveness of Using Technology in Learning English. AsiaCALL Online Journal, 12(2), 24-40. Retrieved from https://asiacall.info/acoj/index.php/journal/article/view/26 
Vargas, J. (2011). Modern Learning: Quizlet in the Social Studies Classroom. Unpublished Master's thesis, Wichita State University.

Wright, B.A. (2016). Transforming vocabulary learning with Quizlet. In P. Clements, A. Krause, \& H. Brown (Eds.), Transformation in language education. Tokyo: JALT.

\section{Biodata}

Nguyen Thanh Thuy is currently a junior of Business English at Banking University of Ho Chi Minh City, Vietnam. Her field of interest is English learning methods, so she chose the topic related to IT application in English learning to present at the conference. This is a great opportunity for her to learn new things and experiment through this event.

Nguyen Dinh Tri is a junior majoring in the English language at Banking University Ho Chi Minh City. To be honest, this is the first research that he has finished and this also is the first time that he has taken part in such an international conference. He hopes that the conference can help him improve himself and develop new skills.

Nguyen Dang Le Quoc Khanh is a junior at Banking University in Ho Chi Minh City, specializing in English. He has a passion for learning languages. He really wants to become multilingual. Honestly, this is the first time he has completed a research project, and it is also the first time he has attended an international conference. He sincerely believes that the conference can widen his horizons.

Same with other members, Mai Huy Hoang is a Banking University Ho Chi Minh City's junior. He is following a Bachelor's Program in Business English. He has used his skills in reading and writing to participate in this study. This is his first research in the study program.

Le Thi Thanh Xuan is currently a junior at Banking University in Ho Chi Minh City, Vietnam. To be honest, she is in charge of learning Business English in accordance with her college's program. This is her first time conducting research at university. 